\title{
Chrome Cation Removal Using Microfiltration Ceramic Membrane From Kaolinite
}

\author{
Heri Sutanto ${ }^{1, *} J_{a s l i n}$ Kkhsan $^{1}$ Endang Widjajanti LFX ${ }^{1}$ Erfan Priyambodo ${ }^{1}$ \\ ${ }^{l}$ Department of Chemistry Education, Faculty of Mathematics and Natural Science, Universitas Negeri Yogyakarta, \\ Jl. Kolombo No.1, Karangmalang, Depok, Sleman, Yogyakarta, Indonesia \\ *Corresponding author. Email: sutantoheri211@gmail.com
}

\begin{abstract}
The increasing activity of the leather tanning industry has resulted in an increasing amount of liquid waste produced. The waste contains heavy metals which are harmful to the environment and human health. Therefore the waste needs to be managed so that the negative impact of this waste can be reduced. The increase in the amount of liquid waste has an impact on increasing the cost of treating this waste. Using inexpensive materials can reduce waste treatment costs. This research aims to make ceramic membranes for application in the processing of leather tanning wastewater. Natural kaolinite is abundant and cheap so it has the potential to produce cheap ceramic membranes. The ceramic membrane is made using kaolinite powder. Polyvinyl alcohol is used as a pore forming agent. The effect of increasing the amount of polyvinyl alcohol adding on membrane characteristics was studied. The variations of the polyvinylalcohol composition studied were $0 \%, 2 \%, 4 \%$ and $6 \%$. The characteristics studied were porosity, morphology, flux, and membrane rejection. The results showed that the greater the polyvinyl alcohol composition, the higher porosity and membrane flux. The rejection value decreases with increasing amount of polyvinyl alcohol. The higher the polyvinyl alcohol composition resulted in an inhomogeneous membrane surface. The resulted membrane were categorized as microfiltration membrane which has membrane pore diameter range of 0.1-10 $\mu \mathrm{m}$.
\end{abstract}

Keywords: kaolinite, chrome, ceramic membrane.

\section{INTRODUCTION}

The rapid industrial growth has resulted in an increase in the quantity of waste produced by industrial processes. The substances contained in waste are in the form of chemicals that are harmful to human health and safety. The leather tanning industry is an industry that processes animal skins into economic value products such as bags, clothes, wallets and shoes. The leather processing process uses large amounts of water. In tanning 1 ton of leather, at least $40 \mathrm{~m}^{3}$ of water is required. The water then mixes with other chemicals and residual substances into wastewater [1]. For example, in India, at least $52,500 \mathrm{~m}^{3}$ of tannery wastewater is produced every day. Wastewater from the tannery used in the industry is contaminated with chromium metal from the tanning process. Chrome is the most commonly used tanning material. $85 \%$ of the world's leather is tanned using chrome [2]. Chrome metal can exist in several forms of oxidation numbers including $\mathrm{Cr}, \mathrm{Cr}^{3+}$, and $\mathrm{Cr}^{6+}$. The $\mathrm{Cr}^{3+}$ form occurs naturally in the human body as an important micronutrient. In high quantity chromium metal has a bad impact on human health. The metal is toxic and carcinogenic [3].

Kaolinite material is a material that is very abundant in nature. This material is also the material most frequently studied because it has an interesting character. Kaolinite is an inexpensive material that is important for application as a ceramic membrane [4].

Currently the use of kaolinite is quite extensive in various fields. Kaolinite is used as a filler in the paper industry, a pigment in the paint industry, as well as a major ingredient in the ceramic industry. Ceramic membranes are more often chosen because they have the advantage of being mechanically strong, resistant to high temperatures, resistant to degradation of chemical compounds and easy maintenance [5].

Ceramic membranes are membranes that have many advantages, currently they are made from materials such as alumina, zirconia, titanium, and silica. However, these materials are not suitable for large-scale 
application because they are expensive [6]. In addition, the membrane manufacturing process must go through high temperatures $\left(1300-1500{ }^{\circ} \mathrm{C}\right)$ so that it requires large energy. Using unrefined natural materials will save the cost of producing ceramic membranes [7]. Therefore, a research was conducted on the manufacture of ceramic membranes from natural kaolinite as a material for making ceramic membranes. Various studies have been carried out to produce ceramic membranes with certain characteristics. The use of various additives has been studied such as addition of organic fibers, graphite, and bamboo charcoal. The addition of these additives affects the characteristics of the ceramic membrane that is made [8].

This research studied the synthesis of a kaolinitebased ceramic membrane to be applied as a filter membrane. This membrane is expected to be able to reduce the chromium metal content in the tannery liquid waste. The use of kaolinite as a filter membrane is expected to produce a cheap membrane. In addition, the filtration method was chosen to make the separation process more energy efficient.

\section{MATERIALS AND METHODS}

\subsection{Materials}

The material used in this research is natural kaolinite taken directly from nature without further processing. Polyvinyl alcohol is used as a pore forming agent. Water is used as a solvent to mix kaolinite and PVA.

\subsection{Membrane Synthesis Methods}

The ceramic membrane is made through homogenization and casting steps. The first stage is the homogenization of a mixture of kaolinite and polyvinyl alcohol using distilled water as a solvent. The second stage is the membrane casting using the dry press method.

\subsection{Characterization Methods}

XRD (X-Ray Diffraction) was used to characterize the diffraction pattern of kaolinite. This method can be used for materials recognition using its specific diffraction pattern so the materials can be confirmed as kaolinite. The used instrument is Rigaku Miniflex 600 Benchtop XRD.

Membrane morphology was characterized using SEM-EDX Phenom Desktop Pro-XL. The data of this characterization method are image of membrane's surface. This data can be used to determine the average pore size of membranes using ImageJ software [9].

Chromes concentration in wastewater before and after it was filtrated was determined with atomic absorbance spectroscopy instrument. The data was used to calculate the rejection value of the membranes.

\section{RESULT AND DISCUSSION}

\subsection{Material Preparation}

This study uses an inexpensive material to produce ceramic membranes at the lowest possible cost. The materials used are natural kaolinite and PVA as additives. This additives was used for membrane modification to get ceramic membrane with desired properties. The kaolinite used is natural kaolinite purchased from the chemical shop Progo and polyvinyl alcohol pro analysis grade purchased from the Chemmix chemical store. The kaolinite used is sieved using a 100 mesh sieve. The kaolinite material was characterized using the XRD method.

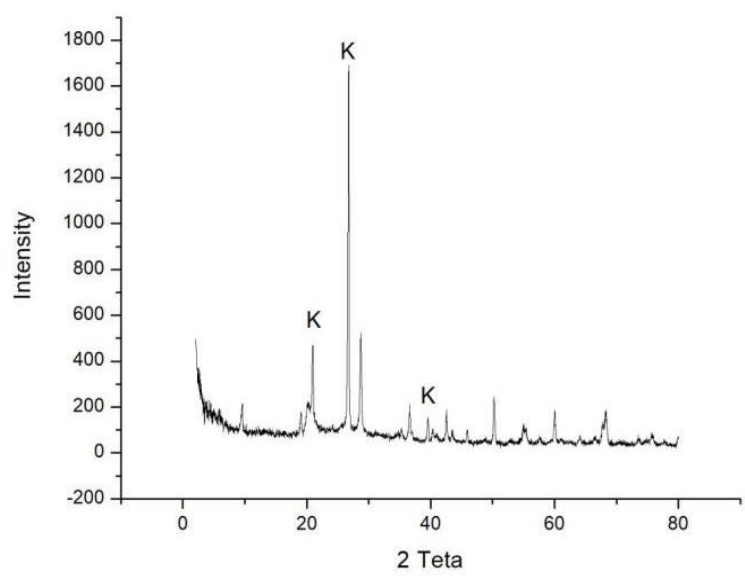

Figure 1. XRD diffraction of kaolinite

In the chart above, it can be confirmed that the material used contains kaolinite minerals. This is shown from the identical peaks of the two XRD data being compared. The $2 \theta$ value identified from the XRD results of the material used shows the $\mathrm{d}$ value of kaolinite. Based on Dewi et al (2018) kaolinite has $2 \theta$ value of $21.32^{\circ}, 26.57^{\circ}, 34.94^{\circ}$, and $38.35^{\circ}$. The $2 \theta$ value identified from experiments were $21.0091^{\circ}, 26.7326^{\circ}$, $36.6321^{\circ}$, and $39.6014^{\circ}$. The peaks marked with the letter $\mathrm{K}$ on the graph indicate the specific peaks of the kaolinite material.

This research studied the effect of adding PVA on the characteristics of the synthesized ceramic membrane. The number of additives added greatly affects the characteristics of the resulting membrane [9]. Therefore, the percentage amount of PVA added to the synthesis of the kaolinite membrane was determined. The percentage of total PVA used was $0 \%, 2 \%, 4 \%$ and $6 \%$.

The method used to synthesize this ceramic membrane is dry press. This method provides the 
advantage of a synthesis that adds additives where the material is homogeneous and has high mechanical rigidity. The dry press method is a good method for avoiding bad impacts due to the effect of shrinkage (shrinkage) on slip casting, namely the production of membranes with low mechanical strength [10].

There were two stages to synthesis the membranes, the homogenization stage of the kaolinite-PVA mixture and the membrane printing stage. The homogenization process uses distilled water as a solvent as was done by Nandi et al (2007). The kaolinite-PVA mixture which has been homogenized is dried first to reduce the moisture content. Excessive water content can cause cracks in the membrane after the sintering process. The crack is a result of shrinkage due to decreased water content due to heating [10].After the drying process, the resulting mixture is a hard solid. The solid is mashed with a mortar and filtered. Solid refinement aims to make the material be casted in the desired shape. The mold used is circular and designed to produce a ceramic membrane in the shape of a circle/chips. The diameter of the casting tool is $3.5 \mathrm{~cm}$. The synthesis of the kaolinite membrane was carried out by a dry press method where the prepared material was casted and pressed. The molding stage produces a kaolinite membrane which is then heated at a temperature of 1100 ${ }^{\circ} \mathrm{C}$. The heating process at $1100{ }^{\circ} \mathrm{C}$ is called the sintering process which aims to strengthen the ceramic membrane. In the sintering stage, polyvinyl alcohol molecules, water, and organic impurities will decompose which leaves pores on the membrane surface [11]. The final result of this stage is a ceramic membrane made from kaolinite, which is ready to be characterized.

\subsection{Characterization of Ceramic Membrane}

\subsubsection{Scanning Electron Microscope (SEM)}

SEM analysis was performed on membrane with and without polyvinyl alcohol added. Surface analysis was carried out at a magnification of 10,000 times. SEM results show that the surface structure of the membrane is similar in that the kaolinite particles form the intergranular space. Research conducted by Rekik et al (2017) showed the same results. Sintering at temperatures below $1100^{\circ} \mathrm{C}$ produces an intergranular surface structure that shows the initial sintering process. At temperatures of $1200^{\circ} \mathrm{C}$ and $1250^{\circ} \mathrm{C}$, the resulting ceramic membrane is tighter. Sintering at temperatures above $1200^{\circ} \mathrm{C}$ makes kaolinite particles agglomerate and produce a denser membrane [12]. Sintering at high temperatures reduces the porosity of the ceramic membrane because mineral particles melt and fuse. The sintering process at lower temperatures focuses more on
There were two stages to synthesis the membranes, the homogenization stage of the kaolinite-PVA mixture and the membrane printing stage. The homogenization process uses distilled water as a solvent as was done by Nandi et al (2007). The kaolinite-PVA mixture which has been homogenized is dried first to reduce the making the membrane at the least possible cost because at lower temperatures less energy is required.

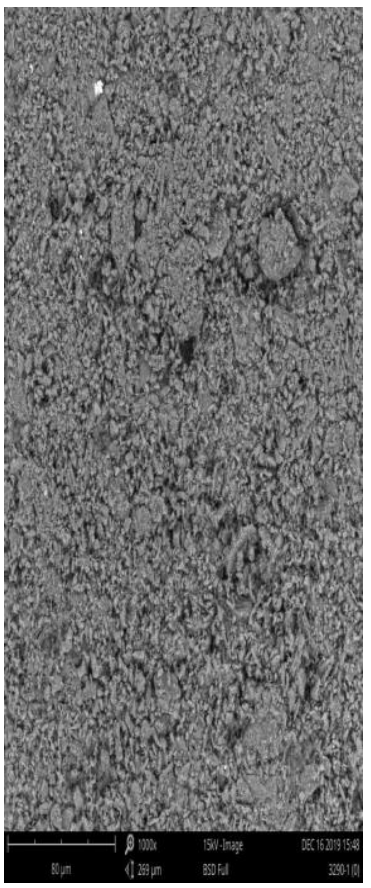

Figure 2. Membrane without PVA addition

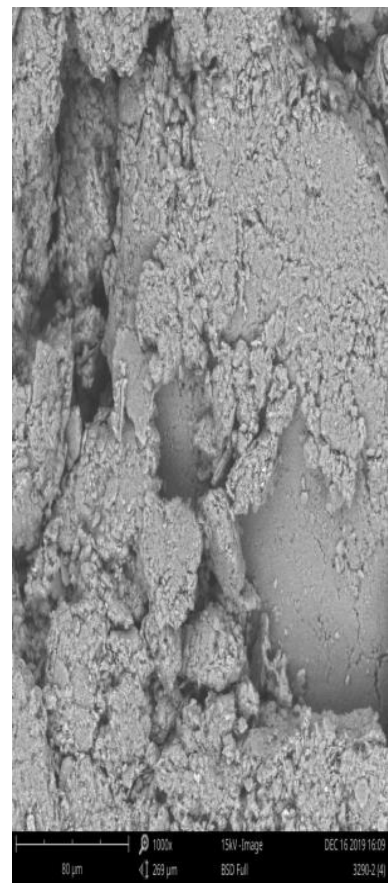

Figure 3. Membrane with PVA addition
The pore diameter of the membrane was determined using ImageJ software based on data from SEM analysis. Based on calculations using the ImageJ application the average pore diameter is $0.984 \mu \mathrm{m}$ and $1.515 \mu \mathrm{m}$. Based on the results of these calculations, the membrane is categorized as a microfiltration membrane. Microfiltration refers to a filtration process that uses a porous membrane to separate suspended particles 0.1 $10 \mu \mathrm{m}$ in diameter. Microfiltration is usually used to hold particles in a suspension solution [7].

\subsubsection{Porosity Measurement}

Measurement of porosity using the Archimedes method as done by Nandi et al. (2007). The data used are wet and dry weight of the membrane. The wet weight of the membrane was obtained by immersing the membrane in distilled water for 24 hours, then the membrane was weighed using analytical scales. The purpose of immersion is to find out how many water molecules can occupy the space in the membrane. The membrane is then heated for 24 hours at a temperature of $100{ }^{\circ} \mathrm{C}$. The purpose of the oven is to remove the 
water content in the membrane from the immersion process. After the oven process, the membrane was weighed using analytical scales to determine the dry weight of the membrane. The difference between the wet weight and the dry weight of the membrane shows the number of water molecules that fill the space in the membrane.

This research studied the effect of adding PVA additives on membrane characteristics. These characteristics are membrane surface morphology, membrane porosity, permeability, and membrane permselectivity. In general, the addition of additives that decompose at high temperatures will increase the porosity of the membrane. These substances generally decompose at temperatures of $200-500^{\circ} \mathrm{C}$. An increase in the number of additional pore-forming additives increased porosity and membrane pore size. An increase in porosity and membrane pore size will result in increased membrane permeability [8].

The results showed that the membrane with the least amount of PVA had the smallest porosity, namely the membrane with the amount of PVA $0 \%$. The membrane with the highest amount of PVA produced ceramic membranes with the highest porosity, namely the membrane with the amount of PVA $6 \%$.

The graph in figure. 4 shows that the greater the amount of PVA addition, the greater the porosity of the membrane. The added PVA functions as a pore forming agent. The pore-forming agent in the synthesis of ceramic membranes will be oxidized leaving to produce pores [11].

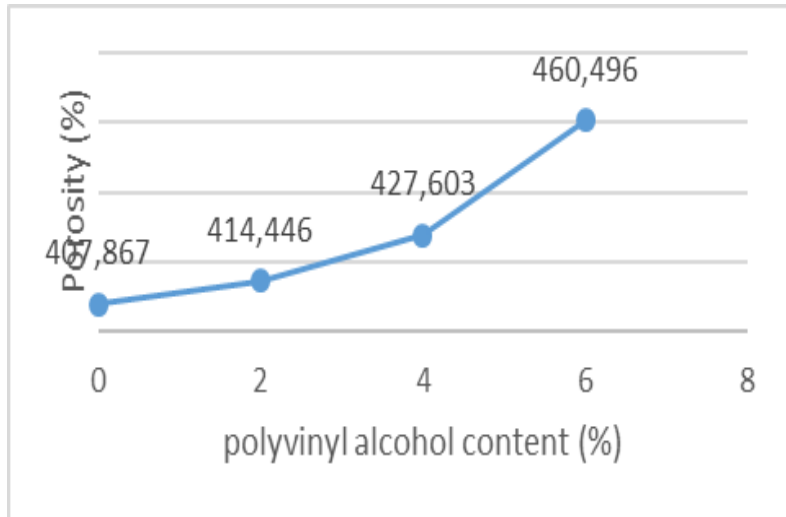

Figure 4. Membrane porosity respect to PVA content

\subsubsection{Filtration Performance of Membrane}

The tannery liquid waste contains chromium metal. This is known based on tests using the AAS instrument. The purpose of making the membrane is to use it as a membrane filter that will filter the tannery liquid waste so as to reduce the chromium metal content in the waste. Liquid waste is processed using a module in the form of a series of pumps and pipes that drain the liquid waste through the membrane. The dead end reactor uses a
Shimidzu brand water pump. In this filtering method, the liquid waste passes through the membrane perpendicularly (dead end). The force generated from the pump presses the waste liquid through the membrane.

The filtering process is carried out for 30 minutes. The parameters sought from this process are the flux value and rejection of the ceramic membrane in filtering the tannery liquid waste. In determining the flux value, the dimensions of the membrane and the volume of permeate that pass through the membrane are first looked for during the filtering process. This flux value was determined for all synthesized membranes.

Based on the experiments that have been carried out, the greater the percentage of PVA in the membrane, the greater the flux value. This is because the percentage of the amount of PVA is proportional to porosity. The increase in the percentage of PVA causes the number of pores in the membrane to increase. As a result of the increase in membrane porosity, it will result in greater flux. A high flux value means that the amount of fluid passes through the membrane quickly. The high flux results in a faster filtration process. However, in several studies high flux was associated with low rejection values so that the filtration process was ineffective [13].

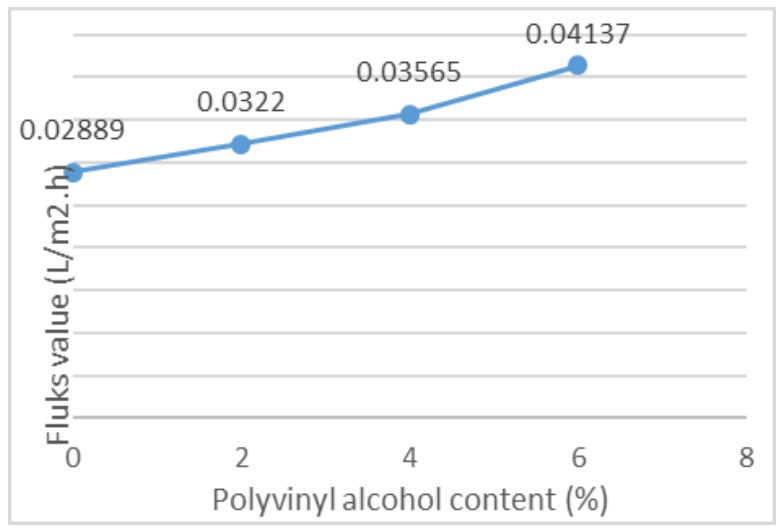

Figure 5. Membrane flux with respect to PVA content

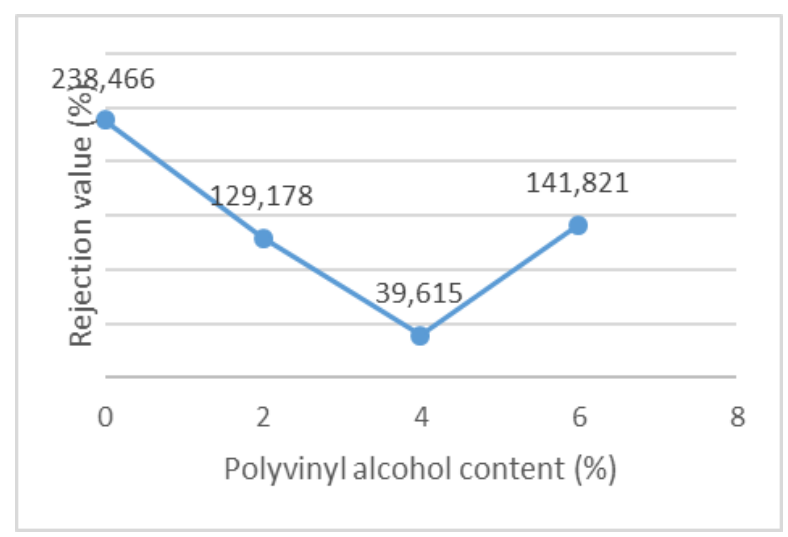

Figure 6. Membrane rejection with respect to PVA content 
The rejection value indicates the ability of the membrane to hold certain particles. The ability of the membrane to hold particles is supported by several characteristics of the membrane material itself. Based on the experiments conducted, the rejection value decreased with the increasing amount of PVA added. It has been stated previously that a high flux is always associated with a low rejection value. The dotted line in the figure shows the tendency of the rejection value to decrease as the percentage of PVA increases. The low rejection value makes the filtration process ineffective.

Filtration of cations using ceramic membranes often gets unsatisfactory results because the size of the cations is too small. Research conducted by Jana et al (2010) used the Michelar enhanced microfiltration (MEMF) method to increase the rejection value of chromate ion filtration. Cetylpyridium chloride (CPC) is used as a micelle forming agent. A rejection value of $100 \%$ was obtained at a CPC / chromate ratio equal to 10. Saikia et al (2010) used a ceramic membrane to filter methylene blue and congo red dyes. The membrane is able to decolorize liquid waste containing methylene blue and congo red dyes with good efficiency. In a study conducted by Abadi et al (2011) using a tubular ceramic membrane to treat oil-contaminated water. The membrane is able to reduce the oil concentration up to 4 mg / L (National Discharge Standard) and the TOC removal efficiency is higher than $95 \%$. Ceramic membranes are more suitable for separating particles with a size larger than the ion size.

The use of membranes made from kaolinite for waste containing cations is generally possible. However, its application must consider the aspects of effectiveness and efficiency. In this study only the physical characteristics, flux and rejection values of the membrane in filtering the tannery liquid waste were reported. The cation that is filtered is the chromium metal cation. For its application on a larger scale, further research is needed. Research that needs to be done includes, among others, the strength of the membrane, the efficiency of the waste treatment time, and many other aspects that need to be studied.

\section{CONCLUSION}

Polyvinyl addition gave the result which membrane has higher porosity. The higher porosity also increased the membranes flux, but the rejection value decreased. The membranes with polyvinyl addition have unhomogeneous morphology.

\section{REFERENCES}

[1] Paul, H.L., Phillips, P.S., Covington, A.D., Evans, P., \& Antunes, A.P.M.(2013). De-chroming Optimization of Chrome Tanned Leather Waste as Potential Poultry Feed Additive:A Waste to Resources.
In Proceding XXXVII Congress of IULTCS. Istanbul, Turkey: IULTCS.

[2] Bacordit, A., Armengol, J., Burgh, S. V. D., \& Olle, L.(2014). New Challanges in Chrome-Free Leathers: Development of Wet-Bright Process. Journal of The American Leather Chemist Association, 109(4),99-109.

[3] Rahmawati, R., \& Suhendar, D.(2015). Sintesis Nanokomposit y-Al2O3-Fe2O3 untuk Adsorpsi Logam Cr(VI). Jurnal Istek, 8(1), 117-128

[4] Nandi, B. K., Uppaluri, R., \& Purkait, M. K.(2007).Preparation and Characterization of Low Cost Ceramic Membranes for Micro-filtration Application. Applied Clay Science, 42, 102-110.

[5] Huang, S. C., Huang, C. T., Lu, S. Y., \& Chou, K. S.(1999). Ceramic/polyaniline Composite Porous Membrane. Journal of Porous Materials, 6, 153-159.

[6] Benito, M., Sanchez, M. J., Pena, P., \& Rodriguez, M. A.(2007). Development of New High Porosity Ceramic Membrane for Treatment of Bilge Water. Desalination, 214, 91-101.

[7] Mulder, M.(1996). Basic Principles of Membrane Technology, 2nd ed.; Kluwer Academic: Dordrecht, The Netherland; Boston, MA, USA.

[8] Yang, Y., Hu, Z., Chang, Q., Liu, H., Yanf, K., \& Wang Y.(2018). Effect of Type and Content of Poreforming Agents on Properties of Porous Alumina Membrane Support. Materials Science and engineering, 452.

[9] Bose, S., \& Das, C. (2015). Sawdust: From Wood Waste to Pore-former in Fabrication of Ceramic Membrane. Ceram. Int., 41, 4070-4079.

[10] Othman, M. H.D., Wu, Z., \& Li, K.(2014). A Microstructure La0.6Sr0.4Co0.2Fe $0.8 \mathrm{O} 3-\delta$ Hollow Fiber Membrane Reactor for Oxidative Coupling Methane. Journal of Membrane Science, 468, 31-41

[11] Obradovic, N., FIlipovic, S., Rusmirovic, J., Postole, G., Marinkovic, A., \& Radic, D.(2018). Formation of Wollanstonite-based Ceramic After Sintering with Yeast as the Pore Forming Agent. Sci. Sinter., 49, 235-246.

[12]Rekik, B., Bouaziz, J .,Deratani, A., \& Baklouti, S.(2017). Naturally Occurring-Kaolin Clays for Microfiltration Aplications. Periodica Polytechnica Chemical Engineering, 61, 3: 206-215.

[13] Huang, S. C., Huang, C. T., Lu, S. Y., \& Chou, K. S.(1999). Ceramic/polyaniline Composite Porous Membrane. Journal of Porous Materials, 6, 153-159.

[14] Saikia, B.J., and Parthasarathy, G., 2010, Fourier transform infrared spectroscopic characterization of kaolinite from Assam and Meghalaya, Northeastern India, J. Mod. Phys., 1, 206-210. 
[15] Abadi, Sareh Rezaei Hosein., Sebzari, Mohammad Reza., Hemati, Mahmood, Rekabdar, Fate,eh., and Mohammadi, Toraj. 2011. Ceramic Membrane Performance in Microfiltration of Oily wastewater. Desalination, 65,222-22. 